\title{
The effect of dynamic operating conditions on nano-particle emissions from a light-duty diesel engine applicable to prime and auxiliary machines on marine vessels
}

\author{
Hyungmin Lee ${ }^{1}$ and Yeonhwan Jeong ${ }^{2}$ \\ ${ }^{I}$ Department of Naval Propulsion System Engineering, Republic of Korea Naval Academy \\ ${ }^{2}$ Department of Naval Architecture and Ocean Engineering, Republic of Korea Naval Academy
}

\begin{abstract}
This study presents the nano-sized particle emission characteristics from a small turbocharged common rail diesel engine applicable to prime and auxiliary machines on marine vessels. The experiments were conducted under dynamic engine operating conditions, such as steady-state, cold start, and transient conditions. The particle number and size distributions were analyzed with a high resolution PM analyzer. The diesel oxidation catalyst (DOC) had an insignificant effect on the reduction in particle number, but particle number emissions were drastically reduced by 3 to 4 orders of magnitude downstream of the diesel particulate filter (DPF) at various steady conditions. Under high speed and load conditions, the particle filtering efficiency was decreased by the partial combustion of trapped particles inside the DPF because of the high exhaust temperature caused by the increased particle number concentration. Retarded fuel injection timing and higher EGR rates led to increased particle number emissions. As the temperature inside the DPF increased from $25^{\circ} \mathrm{C}$ to $300^{\circ} \mathrm{C}$, the peak particle number level was reduced by $70 \%$ compared to cold start conditions. High levels of nucleation mode particle generation were found in the deceleration phases during the transient tests.
\end{abstract}

KEY WORDS: Cold start; DPF; Prime and auxiliary machine; Nano-sized PM; Transient.

\section{INTRODUCTION}

Early diesel engines in heavy-duty trucks, diesel-powered buses, and light-duty vehicles produced black smoke that caused poor visibility and unpleasant odors. Markle and Brown (1996) and Zervas et al. (2005) found that advanced technologies could treat and reduce the emissions from on-road and off-road vehicles. Hagena et al. (2006) found that the improvements in engine technologies included engine design, quality of combustion, fuel spray angle, and atomization of fuel by high pressure injection as well as advanced technologies for fuel formulations and after-treatment.

However, although clean diesel engines with state-of-the-art technologies produce no visible emissions, they emit small particles that form fine dust in the atmospheric and have adverse health effects. Epidemiological studies (Dockery et al., 1993; Lee et al., 2009; Ostro, 1984) have found that small particles can have a negative effect on human health. In addition, many studies have found that particles in the atmosphere are an important factor in mortality and morbidity rates.

Current particulate matter (PM) standards for diesel passenger vehicles regulate particle emissions in terms of the total mass of PM emitted per kilometer traveled. Andersson $(2001 ; 2004)$ found that these regulations are an effective way to control larger-sized particle emissions because the finer particles contribute little to the total mass of PM emissions. The UN-ECE

Corresponding author: Hyumgmin Lee

e-mail:hmsj1226@korea.ac.kr 
GRPE Particle Measurement Program (PMP) was developed recently to improve these emission problems. In addition, new particle number emission regulations will be enforced for diesel passenger vehicles (Andersson et al., 2007; Regulations, 2008).

In the marine boundary layer, the international convention for the prevention of pollution from ships (MARPOL) of the International Maritime Organization (IMO) and the "Blue Sky Series Program" of the U.S. EPA (Environmental Protection Agency) emission regulations for marine vessels with diesel engines are based on gaseous pollutants and mass-based PM. In view of future standards, Kasper et al. (2007) and Dolphin and Melcer (2008) stressed that it is important to characterize nanosized particle emissions.

The operating principles of four-stroke diesel engines for vehicles and marine applications are similar. Light-duty turbocharged common rail diesel engines have been used on commercial and naval ships as small power plants. However, the operating conditions in the two applications are different. Before transitioning to cruising navigation, marine diesel engines go through a transient condition; however, the transition portion of the cruise is small compared to the length of the cruise. In the case of road vehicles, transient drive conditions, such as rapid starts and stops with transient acceleration and deceleration, are dominant. In addition, Welaya et al. (2011) showed that power plants powered by natural gas, diesel, or gasoline fuels can be used as the main propulsion engines and for electric power generation in small ocean-going vessels. In this context, high power diesel engines with bores smaller than $100 \mathrm{~mm}$ were selected to be analyzed in detail.

The purpose of the work presented here was to analyze the particle number and size distribution characteristics of a turbocharged diesel engine with a catalyzed particulate filter under dynamic engine operating conditions such as engine speed and load, cold start, transient, and engine parameters. This type of engine is applicable to main and auxiliary engines on small boats or naval vessels.

\section{EXPERIMENTAL SECTION}

\section{Test engine}

Fig. 1 shows a schematic diagram of a light-duty turbocharged diesel engine that was used to analyze the nano-sized particle characteristics during steady operation and transient conditions. The diesel engine is a single overhead camshaft (SOHC), inline, four cylinder, 2.5 liter turbocharged common rail direct injection (CRDI) engine. Fuel is supplied from the fuel tank to the high pressure pump through the low pressure pump, and the common rail pressure is controlled by the high pressure pump during engine operating conditions. Detailed engine specifications and test fuel properties are given in Table 1 and Table 2 , respectively.

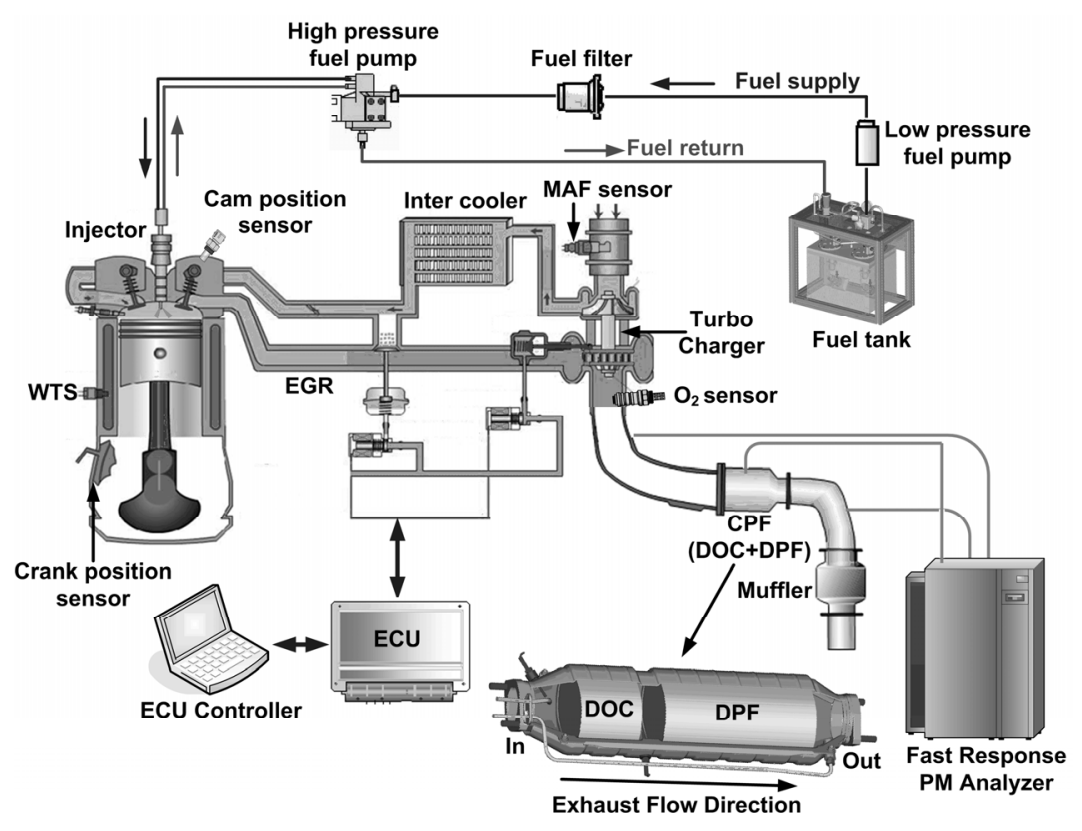

Fig. 1 Schematic diagram of engine experimental system. 


\section{Experimental methodology}

The engine was tested on a dynamic operating test bench at four steady speeds and thirteen loads. The steady-state test conditions are given in Fig. 2. To analyze the effect of after-treatment of the diesel engine, the exhaust gas was sampled at the engine outlet, after the diesel oxidation catalyst (DOC) and after the diesel particulate filter (HM, 289902F000). The DPF was a catalyzed wall-flow type made of silicon carbide ( $\mathrm{SiC}$ ) with 300 cells per square inch (cpsi).

Parameters such as exhaust gas recirculation (EGR) rates and injection timings were varied to evaluate their effects on the particle emission characteristics under mode 5 conditions $(1,500 \mathrm{rpm}$, torque $100 \mathrm{Nm})$. The particle size distribution and number concentration characteristics were analyzed by a differential mobility spectrometer (DMS500). In this experiment, dilution ratio of 250 was used in engine out. Dilution ratio was set to below 100 at post DPF. Dilution air temperature was about $25^{\circ} \mathrm{C}$. In the transient tests, the engine was decoupled with a dynamometer to simulate very aggressive transient operations.

Table 1 Specifications of the test engine.

\begin{tabular}{|c|c|}
\hline Engine type & In-line, SOHC \\
\hline Displacement & $2,497 \mathrm{cc}$ \\
\hline Bore $\times$ Stroke & $91 \mathrm{~mm} \times 96 \mathrm{~mm}$ \\
\hline Compression ratio & $17.7: 1$ \\
\hline Fuel injection & Common rail direct injection \\
\hline Max. power $(\mathrm{hp} / \mathrm{rpm})$ & $145 / 3,800$ \\
\hline
\end{tabular}

Table 2 Properties of the diesel fuel.

\begin{tabular}{|c|c|}
\hline Cetane number & 56 \\
\hline Density $@ 15^{\circ} \mathrm{C}\left(\mathrm{kg} / \mathrm{m}^{3}\right)$ & 828 \\
\hline Ignition point $\left({ }^{\circ} \mathrm{C}\right)$ & 55 \\
\hline Viscosity $\left(\mathrm{mm}^{2} / \mathrm{s}\right)$ & 2.8 \\
\hline Sulfur content $(\mathrm{mg} / \mathrm{kg})$ & 6 \\
\hline
\end{tabular}

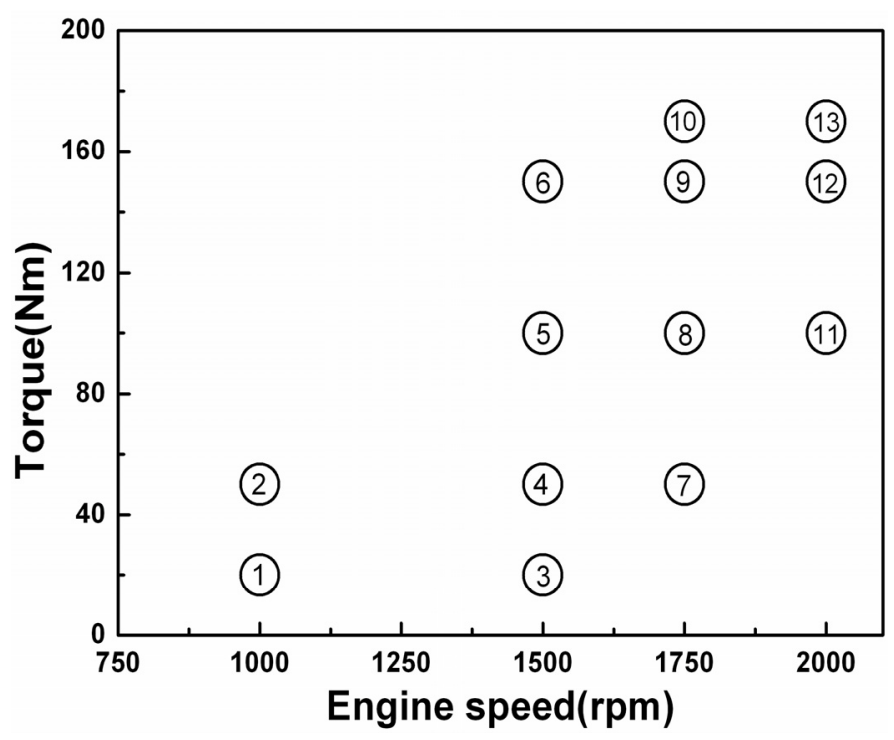

Fig. 2 Engine speed and load conditions. 


\section{RESULTS AND DISCUSSIONS}

\section{Particle concentrations under steady-state conditions}

Fig. 3 shows the exhaust particle number concentrations measured at the engine outlet, after the DOC and after the DPF under steady-state engine operating conditions. The particle number emissions of the engine reached more than $\mathrm{E}+8$ particles/ $\mathrm{cm}^{3}$ at medium speed and low load conditions (modes 3, 4).

Particle emissions decreased at medium speed and load and high speed and load compared to modes 3 and 4 . When compared with the engine outlet PM emission levels, the particle concentrations were generally reduced after the DOC by about an order of magnitude to approximately E +7 particles $/ \mathrm{cm}^{3}$. Downstream of the DPF, particle emissions were drastically reduced by 3 to 4 orders of magnitude compared to after the engine and after the DOC.

Diesel exhaust after-treatment includes a DOC to eliminate HC and CO and a DPF to reduce PM. The DOC removes gaseous precursors to the soluble organic fraction (SOF), and the DPF traps solid particles. Andrea and Maricq (2008) and Ntziachriros et al. (2006) found that gaseous emissions generally were oxidized inside the oxidation catalyst, but their components passed through the DOC because it is not a filter and cannot trap the components. The short residence time of particles inside the DOC leads to reduced oxidation rates of carbon. Therefore, the DOC had a small effect on reducing particle emissions.

The total PM concentration levels reached about E+5 particles $/ \mathrm{cm}^{3}$ downstream of the DPF in modes 12 and 13 . This result can be explained by catalytic soot oxidation inside the DPF due to high exhaust gas temperatures(about $360{ }^{\circ} \mathrm{C}$ and $380{ }^{\circ} \mathrm{C}$ each) at high speed and load conditions. Schmidt et al. (2007) and Wirojaskunchai et al. (2007) found that small carbon components naturally generated from the partial oxidation of accumulated particles inside the catalyzed DPF in some low temperature are thought to have led to the increased particle emissions.

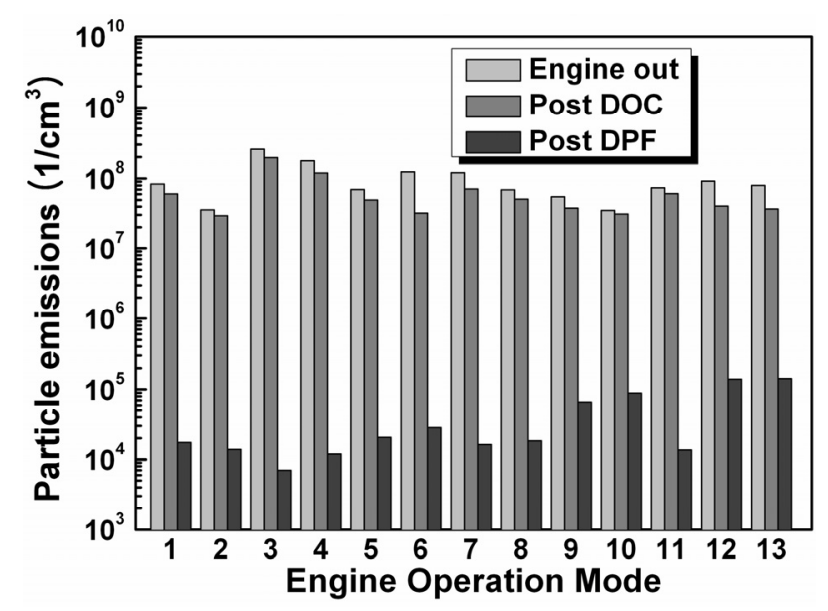

Fig. 3 Particle number emissions for different engine test modes.

\section{Particle size distribution with fuel injection timings}

The PM size distributions in an internal combustion engine are generally classified into nucleation and accumulation modes, which are distinguished by the particle diameter. Kittelson (1998) found that the nucleation and accumulation modes have particle diameters less than about $50 \mathrm{~nm}$ and from $50 \mathrm{~nm}$ to $1,000 \mathrm{~nm}$, respectively; however, the boundary between the nucleation and accumulation modes is variable.

The fuel injection timing of the engine was varied by increments of $2.5^{\circ} \mathrm{CA}$ units from BTDC $5^{\circ} \mathrm{CA}$ to ATDC $7.5^{\circ} \mathrm{CA}$ while the engine was running at mode 5 conditions. Mode 5 was selected because this operation condition is greatly used in real small vehicle The EGR function was removed. Fig. 4 shows the particle size distribution and number concentrations of the exhaust after exiting the engine. The quantities on the abscissa and ordinate represent the aerodynamic particle diameter and the PM number concentrations, respectively. The $d N / d \log D_{p}$ term represents the normalized value of the particle size. As the fuel injection timing was retarded from BTDC $5^{\circ} \mathrm{CA}$ to ATDC $7.5^{\circ} \mathrm{CA}$, the nucleation and accumulation mode concentration levels gradually increased. 
Particles mainly consist of carbonaceous agglomerates that are generated shortly after the start of combustion. Retarded fuel injection timing results in incomplete combustion, so the unburned hydrocarbons are increased. In addition, injection timing affects the residence time for primary soot particle oxidation. As injection timing is advanced, the particles are reduced due to the increased residence time for soot oxidation.

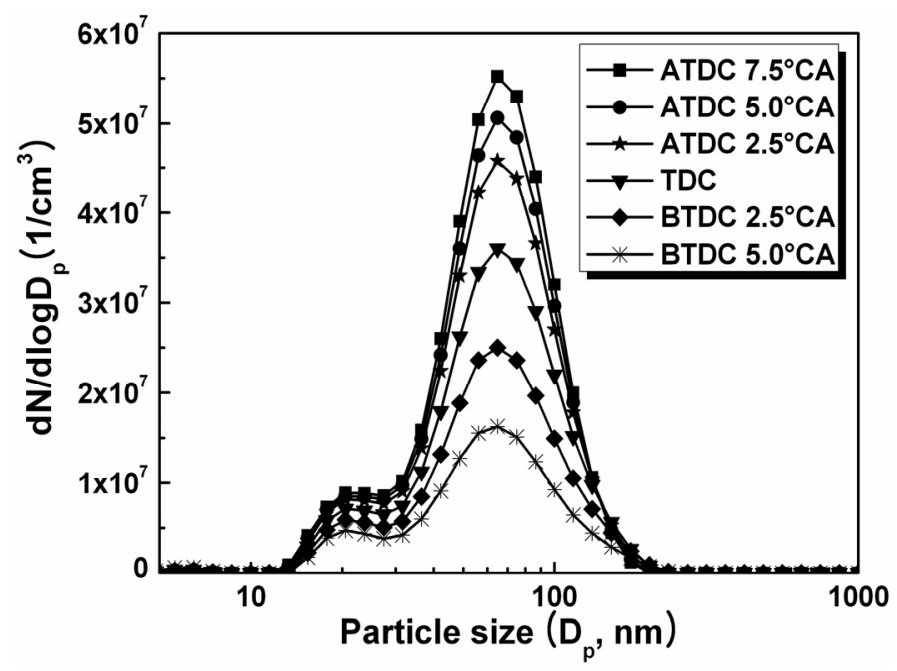

Fig. 4 Particle size distributions with various injection timings.

\section{Particle size distribution with EGR rates}

Exhaust gas recirculation (EGR) rates were varied by increments of $10 \%$ from EGR $0 \%$ to EGR $30 \%$ under mode 5 conditions, while the fuel injection timing was held fixed. Fig. 5 shows the particle size distributions and number concentrations for the different EGR rates. The use of EGR increased the particle number, and the emitted particles increased in size as the EGR increased from $0 \%$ to $30 \%$. This effect was caused by the combustion state of a gaseous mixture composed of air and exhaust gases. Because of the decreased availability of oxygen in the induction air, the rich combustion is thought to generate soot particles and reduce soot oxidation.

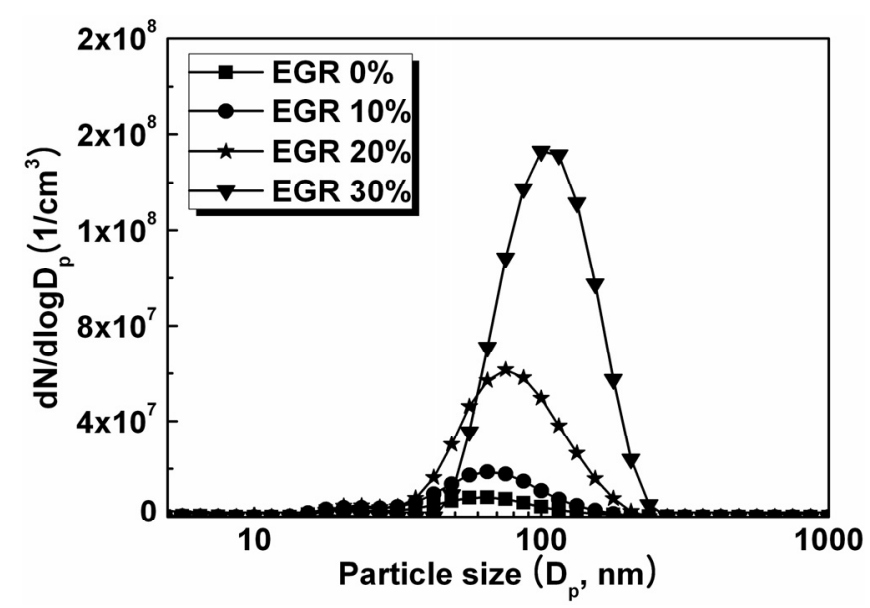

Fig. 5 Particle size distributions with various EGR rates.

\section{Particle emission characteristics in the start phase}

Fig. 6 shows the time-resolved particle emission traces at different temperatures inside the DPF during a cold start. The location of thermocouple $(0.5 \mathrm{~mm})$ is inside DPF. The temperature inside the DPF was controlled by a heated line from an external heater, temperature profile of DPF is not measured. The test results show that particle emissions gradually decreased as 
the temperature inside the DPF increased. Peak particle emission levels differed greatly above $100{ }^{\circ} C$, but the exhaust particle concentrations were similar at idle after the cold start.

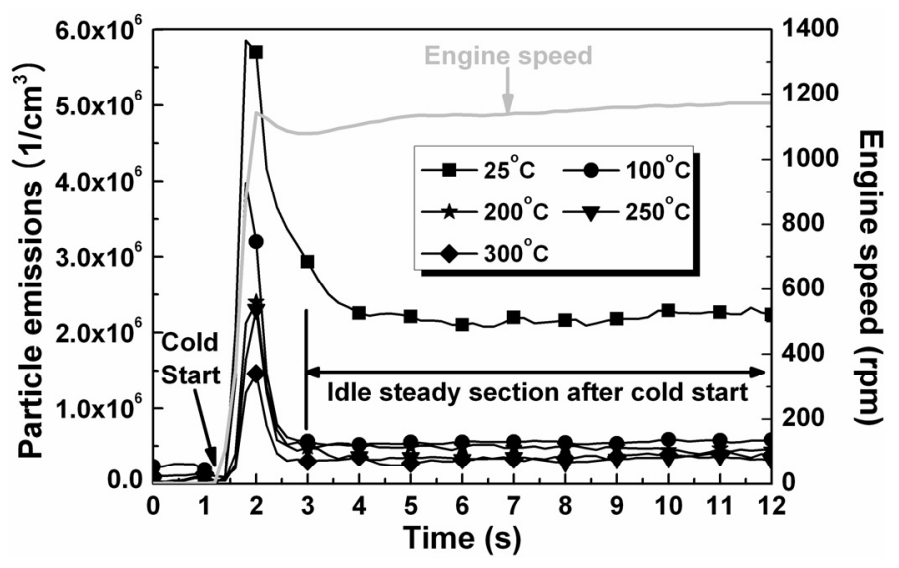

Fig. 6 Effect of temperature inside DPF on the reduction of particle emission during cold start.

Several particle deposition mechanisms operate in a filter. In particular, the filtration efficiency is closely connected to the temperature inside the particulate filter. A rise in temperature inside the filter leads to an increase in the diffusion velocity of the inflow particle, so fine particles can be trapped by the depth filtration effect (Fig. 7). Diffusion deposition occurred as a result of a particle emission concentration gradient $(\Delta C)$. In Fig. 7, time domain to analyze the particle size distribution is from cold start to 12 seconds.

The Peclet number is used to explain this effect. Wirojaskunchai et al. (2007) demonstrated that the Peclet number can be an effective parameter in comparing the filtration at low temperatures in the DPF. The filtration efficiency $\left(E_{D}=2 P e^{-2 / 3}\right)$ due to diffusion is a function of the dimensionless Peclet number $\left(P e=d_{f} U_{0} D\right)$. This parameter is inversely proportional to the diffusion coefficient (D), which increases with temperature. Therefore, fine particles are not deposited on the surface of the filter and pass through the pores in the filter because the diffusion velocity $\left(V_{D} \sim D \cdot \Delta C\right)$ of the particles drops due to insufficient DPF temperature. The coolant temperature, which affects the particle emission concentration levels, is a variable engine parameter.

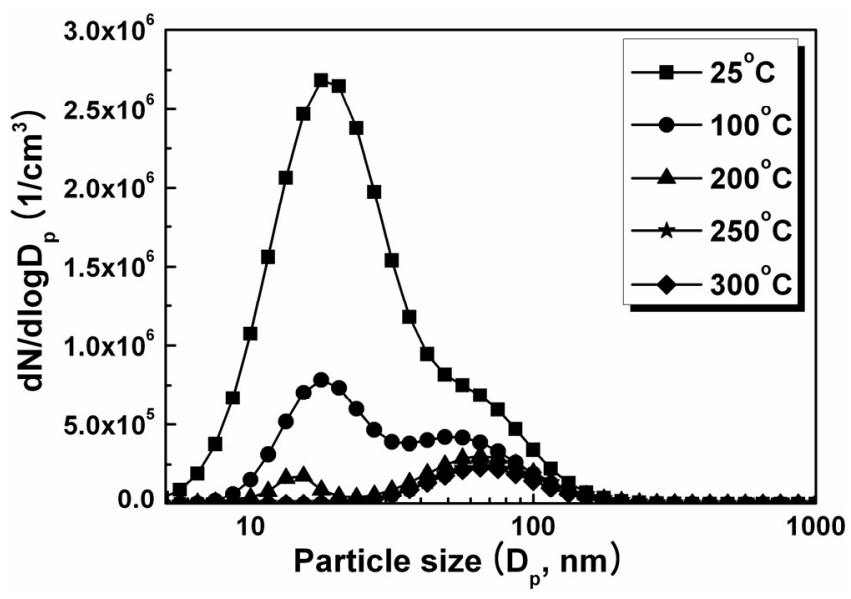

Fig. 7 Particle number and size distributions from Fig. 6.

Fig. 8 shows the time-resolved particle emission traces with coolant temperatures during aggressive transient operations. Grey line means cold coolant temperature, bold line means fully warm up state. The EGR function was removed for the transient tests, and the coolant temperature was continuously controlled by an external coolant controller $\left(25 \pm 2{ }^{\circ} \mathrm{C}, 85 \pm 2{ }^{\circ} \mathrm{C}\right)$.

The peak particle level during the cold start (coolant temperature: $25 \pm 2{ }^{\circ} \mathrm{C}$ ) was an order of magnitude higher than during hot restart (coolant temperature: $85 \pm 2{ }^{\circ} \mathrm{C}$ ), but the exhaust particle emissions had similar levels after cold start and hot restart. 
The PM number concentrations correlate with rapid acceleration; however, they decrease during the second and third aceleration phases. The decrease is due to the engine reaching normal operation conditions (the oil and engine metal temperature increased) after the first acceleration phase, although the coolant temperature is still cold. Also of note is the PM spike at the end of each rapid deceleration phase.

This spike appears to correlate with fuel cut. The nucleation mode particles are generated by self-nucleation when the accumulation mode particles are reduced as a result of cooling when the fuel cut is occurred. Fuel cut function is controlled by engine control unit (ECU) to improve the fuel economy during rapid deceleration period in small vehicles installed this type engine.

Residual components inside cylinder are supposed to be generated to nucleation particle with PM self nucleation by cooling during the fuel cut period. The analysis indicates that the PM characteristics during rapid deceleration correlate with the nucleation mode particles (Fig. 9).

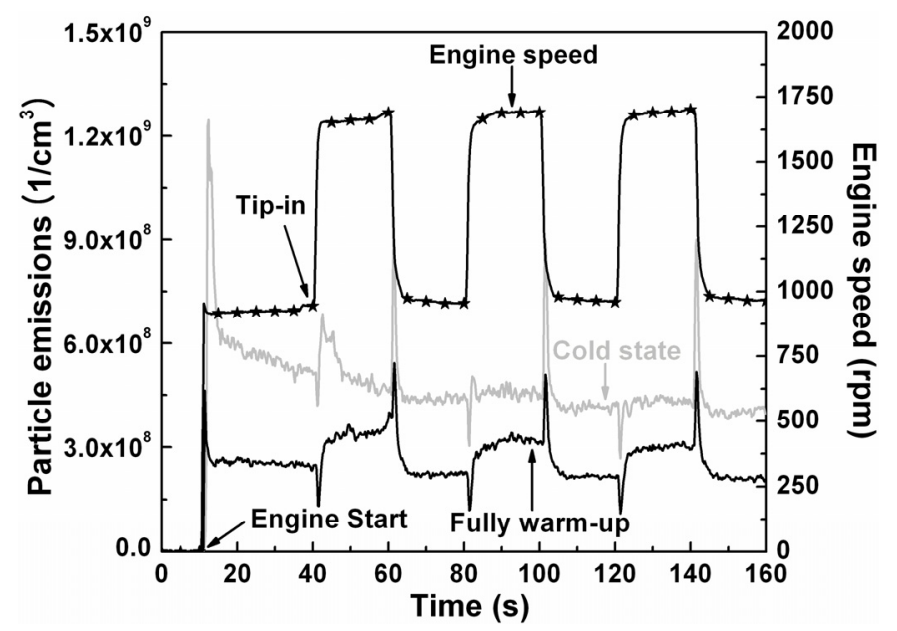

Fig. 8 Time-resolved particle emission traces at different coolant temperatures.

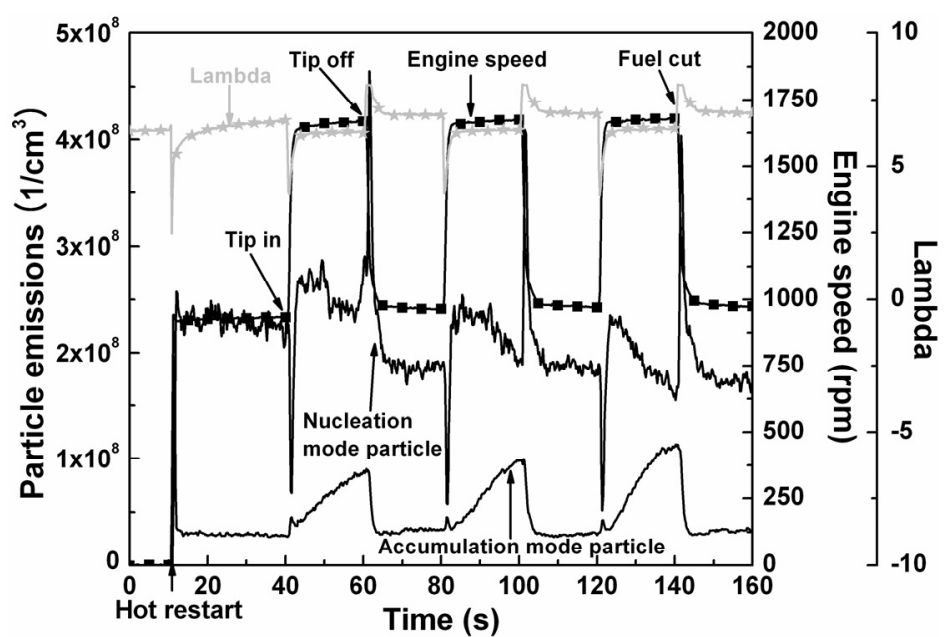

Fig. 9 Time-resolved nucleation and accumulation mode particle traces during rapid acceleration and deceleration (fully warmed-up, EGR 0\%).

\section{CONCLUSIONS}

The particle emission characteristics of a common rail light-duty turbocharged diesel engine typical of marine main and auxiliary machines were analyzed under dynamic engine operating conditions. The particle size characteristics were compared with EGR rates and fuel injection timings. Based on the results of these studies, the following conclusions can be drawn: 
The effect of the DOC on the reduction in particle number emission was insignificant. However, particle number levels were reduced by 3 to 4 orders of magnitude downstream of the DPF. At high speed and load conditions, partial regeneration occurred inside the DPF due to the high exhaust gas temperatures, which led to increased particle number concentrations.

As the fuel injection timing was varied from advanced to retarded conditions, both nucleation and accumulation mode particles increased in number. Advanced injection timing at partial load conditions leads to stable combustion compared to retarded conditions. Stable combustion causes soot oxidation, which is thought to decrease the number of exhaust particles.

The particle number emissions increase as the EGR percentage increases. This effect can be explained by the decreased availability of oxygen in the induction air. The potential for rich combustion is thought to generate soot particles and reduce soot oxidation.

The reduction of fine particles during cold starts is considerably dependent on the temperature inside the DPF. As the temperature inside the DPF increased from $25^{\circ} \mathrm{C}$ to $300{ }^{\circ} \mathrm{C}$, the maximum particle emission level decreased by $70 \%$ from the cold start conditions.

Particle emissions were greater at cold coolant temperatures than at fully warm conditions. Moreover, the residual components inside the cylinder are caused by the increase of nucleation mode particles due to the self-nucleation of PM by cooling inside the cylinder by the fuel cut during rapid deceleration.

\section{ACKNOWLEDGEMENTS}

This research was funded by the Naval Institute for Ocean Research in 2012.

\section{REFERENCES}

Andrea, D.F. and Maricq, M.M., 2008. Diesel nucleation mode particles: Semivolatile or solid?. Environment Science and Technology, 42(21), pp.7597-7962.

Andersson, J., Wedekind, B., Hall, D. and Stradling, R., 2001. DERT/SMMT/CONCAWE particle research programme: light-duty results. SAE paper, 2001-01-3577.

Andersson, J., Clarke, D. and Watson, J.A., 2004. UK particulate measurement programme (PMP): A near US 2007 approach to heavy duty diesel particulate: measurements comparison with the standard European method. SAE Paper, 200401-1990.

Andersson, J., Giechaskiel, B., Bueno, R.M., Sandbach, E. and Dilara, P., 2007. Particle measurement programme (PMP) light-duty inter-laboratory correlation exercise (ILCE_LD) final report. Joint Research Center, EU.

Dockery, D., Pope, C. and Wu, X., 1993. An association between air pollution and mortality in six US cities. New England Journal of Medicine, 329(24), pp.1753-1759.

Dolphin, M.J. and Melcer, M., 2008. Estimation of ship dry emissions. Naval Engineers Journal, 120(3), pp.27-36.

Hagena, J.R., Fillipi, Z.S. and Assanis, D.N., 2006. Transient diesel emission: analysis of engine operation during s tip-in. SAE paper, 2006-01-1151.

Kasper, A., Aufdenblatten, S., Force, A., Mohr, M. and Burtscher, H., 2007. Particulate emission from a low-speed marine diesel engine. Aerosol Science and Technology, 41(1), pp.24-32.

Kittelson, D.B., 1998. Engines and nanoparticles: A review. Journal of Aerosol Science, 29(5-6), pp.575-588.

Lee, H., Kim, J.W., Myung, C.L. and Park, S., 2009. Experimental investigation of nanoparticle formation characteristics from advanced gasoline and diesel fueled light duty vehicles under different certification driving mode. Journal of Mechanical Science and Technology, 23(6), pp.1591-1601.

Markle, S.P. and Brown, A.J., 1996. Naval ship engine exhaust emission characterization. Naval Engineers Journal, 108(5), pp.37-47.

Ntziachritos, L., Mamalos, A., Samras, Z., Rexeis, M. and Hausberger, E., 2006. Diesel particle exhaust emissions from light duty vehicles and heavy duty engines. SAE paper, 2006-01-0866.

Ostro, B., 1984. A research for a threshold in the relationship of air pollution to mortality: a reanalysis of London winters. Environmental Health Perspectives, 58, pp.397-399. 
Regulations, 2008. Commission regulation (EC) No 632, Official Journal of the European Union. [online] Available at: $<\mathrm{http}: / /$ eur-lex.europa.eu> [Accessed 15 March 2012].

Schmidt, N., Root, T., Wirojsakunchai, E., Schroeder, C., Kolodziej, D.E., Foster, T. and Suga, T., 2007. Detailed diesel exhaust particulate characterization and DPF regeneration behavior measurement for two different regeneration system. SAE paper, 2007-01-1063.

Welaya, Y.M.A., Morsy EI Gohary, M. and Ammar, N.R., 2011. A comparison between fuel cells and other alternatives for marine electric power generation. International Journal of Naval Architecture and Ocean Engineering, 3(2), pp. 141-149.

Wirojaskunchai, E., Schroedoer, E., Kolodziej, C., Foster, D.E., Schmidt, N., Root, T., Nevius, T., Kusaka, T. and Suga, T., 2007. Detailed diesel exhaust particulate characterization and real-time DPF filtration efficiency measurements during PM filling process. SAE paper, 2007-01-0320.

Zervas, E., Dorlhène, P., Forti, L., Perrin, C., Momiaue, J.C., Monier, R., Ing, H. and Lopez, B., 2005. Interlaboratory test of exhaust PM using ELPI. Aerosol Science and Technology, 39(4), pp.333-346. 